\title{
SERVIÇO SOCIAL E ACESSO À JUSTIÇA - REFLEXÕES COM BASE NA PRÁTICA DE MEDIAÇÃO FAMILIAR
}

\author{
Eunice Teresinha Fáverol \\ Elisangela Pereira Queiros Mazuelos ${ }^{2}$
}

\section{RESUMO}

O objetivo deste texto é trazer à reflexão alguns aspectos da prática do Serviço Social enquanto possibilidade de acesso à justiça, com destaque para uma experiência em processos de mediação familiar desenvolvida na área da assistência jurídica. Nele é enfatizada a particularidade da intervenção do Serviço Social, revelando-se fundamental enquanto possibilitadora de visibilidade das expressões da questão social, que não raro encontram-se na origem do rompimento de vínculos sociais e familiares que culminam em ações judiciais.

PALAVRAS-CHAVE: Acesso à Justiça, Mediação Familiar, Prática Profisssional, Serviço Social

\section{SERVIÇO SOCIAL E ACESSO À JUSTIÇA ${ }^{3}$}

O Serviço Social tem como um dos eixos do seu projeto profissional na contemporaneidade o trabalho na direção do acesso, da garantia e da efetivação de direitos à população que faz uso dos serviços que presta. Da mesma maneira, a justiça social, a cidadania, a democracia, a liberdade, a não-discriminação, são fundamentais em sua ação, todos eles explicitados no Código de Ética Profissional do Assistente

\footnotetext{
${ }^{1}$ Assistente Social, $11^{a}$ secretária da Associação de Assistentes Sociais e Psicólogos do Tribunal de Justiça do Estado de São Paulo. Mestre e Doutora em Serviço Social pela PUCSP. Professora da Universidade Cruzeiro do Sul.

${ }^{2}$ Assistente Social na área da Assistência Judiciária da Universidade Cruzeiro do Sul. Especialista em Famílias pela UNICSUL. Mestre em Serviço Social pela PUCSP.

${ }^{3}$ Este artigo revisto e atualizado tem como base partes de texto publicado na Revista UNICSUL n ${ }^{\circ} 15$. São Paulo, 2007 (circulação restrita). 
Social, compondo o conjunto dos princípios fundamentais do exercício profissional ${ }^{4}$. Esses princípios, em uniformidade com a lei que regulamenta a profissão ${ }^{5}$ e o conteúdo da formação expresso no currículo em vigor, conforme estabelecido pela Associação Brasileira de Ensino e Pesquisa em Serviço Social - ABEPSS - devem, portanto, ser inerentes ao exercício profissional. Dessa maneira, são princípios a serem exercitados em ações coletivas e na concretude do cotidiano, nas relações profissionais estabelecidas nos diferentes espaços de intervenção.

Nos mais variados espaços sócio-ocupacionais nos quais o assistente social atua, ele depara com segmentos populacionais - adultos, idosos, crianças, adolescentes - na maioria das vezes em situação de vulnerabilidade social, em conseqüência de processos de exclusão ou de não-inclusão no mundo do trabalho formal, ou vivendo por meio do trabalho precário. Trata-se de sujeitos que, ao mesmo tempo, têm dificuldades ou limitações de acesso a direitos sociais que deveriam ser assegurados por políticas sociais, como educação, saúde, moradia adequada, alimentação, cultura, lazer, segurança e, sobretudo, o trabalho digno. Diante de uma realidade marcada pela espoliação, a busca do Serviço Social muitas vezes acontece como possibilidade ou enquanto esperança de acesso aos chamados benefícios sócio-assistenciais instituídos por programas muitas vezes focalizados, instituídos por políticas sociais.

No âmbito dos direitos, o acesso à justiça social se apresenta enquanto direito ao usufruto de bens e serviços que possibilitem uma vida com dignidade, que garantam a cidadania, isto é, a possibilidade de viver, plenamente, como sujeitos de direitos. Justiça social nesta perspectiva vincula-se a direitos constitucionalmente assegurados, ainda que a legislação social, tanto as de caráter universal, como a saúde e a educação,

\footnotetext{
${ }^{4}$ Código de Ética do Assistente Social. Resolução CFESS, nº 273, de 13 de março de 1993.

${ }^{5}$ Lei no ${ }^{\circ} 8.662$, de 7 de junho de 1993 (que revoga a Lei no 3.252 , de 27 de agosto de 1957). Revista Serviço Social \& Saúde. UNICAMP Campinas, v. IX, n. 9, Jul. 2010
} 
por exemplo, como as focalizadas, caso de algumas vinculadas à assistência social, não estejam sendo efetivadas integralmente.

A realidade social também revela que o direito de acesso à justiça por meio do Poder Judiciário, instituição que possui como competência, na divisão dos poderes, a aplicação da lei - que, em tese, deve garantir a distribuição da justiça - visando garantir direitos fundamentais e sociais, está distante de ser assegurado a grande parcela da população, ou o seu acesso pelos setores populares tem sido precário, na medida em que, historicamente, esse acesso tem sido privilégio da população que dispõe de recursos financeiros para remunerar um advogado e as custas processuais. Pode-se afirmar que a justiça, nesse sentido, tem classe social.

Acessar um defensor público em São Paulo, por exemplo, tem se revelado, geralmente, um processo permeado por dificuldades, entre elas, de comunicação e de distâncias geográficas, difíceis de serem ultrapassadas. E, quando ultrapassadas, os sujeitos deparam com a longa 'distância' temporal do trâmite de um processo, em razão do volume de trabalho, da burocracia, do apego a ritos formais pelo meio judiciário, que resiste à inovação. Somam-se a isso as dificuldades existentes em muitos dos serviços de assistência judiciária, de dar conta de acompanhamento sistemático dos processos sob sua responsabilidade, pelo fato de nem sempre estarem suficientemente aparelhados - material e em recursos humanos, para o atendimento das complexidades e do volume das demandas.

Para exemplificar, apresenta-se a seguir algumas situações que tramitaram na Justiça da Família e das Sucessões na capital paulista, envolvendo pessoas pobres, assistidas por defensores públicos ${ }^{6}$ :

\footnotetext{
${ }^{6}$ As informações transcritas foram obtidas em autos processuais consultados. Revista Serviço Social \& Saúde. UNICAMP Campinas, v. IX, n. 9, Jul. 2010
} 
- Uma avó, cuja família vivia com renda no valor de um salário mínimo e meio, requer a tutela de um neto com síndrome de Down, para pleitear o direito dele ao Benefício da Prestação Continuada BPC. A mãe do adolescente cumpria pena de prisão e o pai havia sido assassinado. Pelo fato de desconhecer e não ter sido informada de que poderia pleitear tal medida também na Vara da Infância e Juventude, onde os processos geralmente tramitam com maior rapidez e não é necessário defensor para esse tipo de ação, deslocou-se de sua residência, localizada em um bairro periférico da capital, em direção ao centro da cidade, em uma madrugada, para chegar em tempo de conseguir senha para atendimento no serviço público de assistência judiciária. Foi dada entrada em seu processo e, dois anos depois ${ }^{7}$, os autos foram remetidos ao Serviço Social para realização de estudo social. Nesse período, recebeu poucas e desencontradas informações sobre o andamento do processo, sendo que o direito do jovem e da avó de acesso à justiça via Poder Judiciário permaneceu 'aguardando em uma prateleira' de um cartório.

- Uma mãe, trabalhadora em serviços de limpeza e moradora em área de favela, separada do marido, requer a regulamentação de guarda dos filhos para passar a receber a "Renda Mínima". O benefício, que já havia sido concedido à sua família, estava em nome do ex-marido e pai das crianças, que, com a separação, deixou de lhes repassar o dinheiro. Aproximadamente dois anos após ${ }^{9}$ dar entrada à ação judicial por meio de órgão público de assistência judiciária, o processo foi remetido para estudo social, para posterior decisão judicial, ainda que as informações constantes nos autos indicassem a precariedade de condições de vida da família, o que poderia ser considerado suficiente para a imediata decisão judicial. $\mathrm{Na}$ ocasião em que chegou para o estudo social, a família já havia perdido o direito ao benefício do programa em razão do tempo transcorrido (na medida em que, anualmente, ocorria o recadastramento das famílias, bem como o governo municipal estava numa nova gestão, acontecendo alterações no programa de transferência de renda).

\footnotetext{
${ }^{7}$ Grifo nosso.

${ }^{8}$ Programa municipal de transferência de renda.

${ }^{9}$ Grifo nosso.
} 
Esses dois breves relatos, exemplares do avesso do direito, explicitam e denunciam o não acesso à justiça ou a discriminação no acesso à justiça, em razão da condição social dos sujeitos.

Nesse sentido, Boaventura de Souza Santos nos revela que existe uma discriminação no acesso à justiça em razão de condicionantes econômicos, que se apresentam de maneira evidente. Nessa direção, ele relaciona alguns fatores que considera como responsáveis pela distância entre grande parte dos cidadãos e a justiça:

[...] os cidadãos de menores recursos tendem a conhecer pior os seus direitos e, portanto, a ter mais dificuldades em reconhecer um problema que os afeta como sendo problema jurídico; [...] mesmo reconhecendo o problema como jurídico, como violação de um direito, é necessário que a pessoa se disponha a interpor a ação. Os dados mostram que os indivíduos das classes mais baixas hesitam muito mais que os outros em recorrer aos tribunais mesmo quando reconhecem estar perante um problema legal; [...] quanto mais baixo é o estrato sócioeconômico do cidadão menos provável é que conheça advogado ou que tenha amigos que conheçam advogados, menos provável é que saiba onde, como e quando pode contratar o advogado, e maior é a distância geográfica entre o lugar onde vive e a zona da cidade onde se encontram os escritórios de advocacia e os tribunais (1989, p. 49).

O acesso à justiça por meio de sistemas de assistência judiciária (defensores remunerados pelo Estado para prestarem atendimento à população que não reúne condições financeiras para cobrir as despesas de uma ação; defensoria pública - prevista 
na constituição brasileira ${ }^{10} \mathrm{e}$ ainda não instaladas em alguns Estados brasileiros, ou instaladas em condições aquém da necessidade, como é o caso Estado de São Paulo) tem sido limitado, na medida em que esses sistemas, geralmente, não têm sido aparelhados em condições suficientes - materiais e de recursos humanos - para responder a contento às demandas. Daí a necessidade de buscar a ampliação e a qualificação desses serviços, para os quais os programas de extensão das universidades, dentre outros, podem trazer importantes contribuições, ainda que não devam substituir a responsabilidade pública do Estado na efetivação desse direito do cidadão.

Nos últimos anos alguns movimentos direcionados à ampliação do acesso à justiça, dentre eles, a assistência judiciária e a defesa dos direitos difusos, vêm se fazendo mais presentes na realidade brasileira. Nessa direção, Cólman realiza estudos que apontam para um movimento, que

[...] combina o estímulo à assistência judiciária e à defesa dos direitos difusos com o estímulo a uma gama de reformas no sistema de aplicação das leis envolvendo mudanças de procedimentos, criação de novos tribunais, utilização de leigos e para-profissionais, profissionais de outras áreas ou pessoas especialmente treinadas como agentes de justiça (inclusive como juízes, intermediadores, defensores) e mecanismos para evitar litígios ou resolvê-los em outras esferas externas ao sistema jurídico (2004, p. 130).

Dentre esses espaços sócio-ocupacionais, que podem ser vinculados ao chamado campo sociojurídico, conforme tem sido denominado no âmbito do Serviço 
Social $^{11}$, a presença do assistente social em equipes que prestam assistência judiciária à população vem se mostrando fundamental. Sua participação tem sido chamada para diversas ações, desde a identificação das demandas e articulações com a rede social, até como responsável pela organização e desenvolvimento de trabalhos voltados para a mediação, conciliação e resolução de litígios no âmbito judicial e extrajudicial.

Trabalhando em consonância com a garantia de direitos, o profissional de Serviço Social está habilitado a lidar com uma diversidade de situações, expressas por pessoas que vivem em condição de vulnerabilidade social, que passam por experiências permeadas por violências - social e interpessoal, com vínculos sociais e familiares esgarçados ou rompidos, com o sofrimento social provocado por essas rupturas e pela humilhação da ausência de acesso a direitos. Nesse contexto, a possibilidade de ser atendido e ouvido por um profissional que, entre suas ações, desenvolve reflexões e realiza esclarecimentos relativos a direitos, e que pode possibilitar um espaço facilitador de diálogo, de compreensão e de crítica entre os membros do grupo familiar a respeito dos problemas e dilemas que vivenciam - pontual ou cronicamente, pode ser uma maneira ágil e viável na direção do acesso à justiça.

Assim, um serviço de mediação familiar como projeto de trabalho profissional, em um espaço de assistência jurídica que atua em ações relacionadas à Justiça de Família pode possibilitar efetivas intervenções em Serviço Social, de maneira coerente com o projeto profissional. Aplicando os conhecimentos teóricos e éticos que dão sustentação à profissão por meio de metodologias operativas que possibilitem um

\footnotetext{
11 "Campo (ou sistema) sociojurídico diz respeito ao conjunto de áreas em que a ação do Serviço Social articula-se a ações de natureza jurídica, como o sistema judiciário, o sistema penitenciário, o sistema de segurança, os sistemas de proteção e acolhimento como abrigos, internatos, conselhos de direitos, dentre outros. O termo sociojurídico, enquanto síntese dessas áreas, tem sido disseminado no meio profissional do Serviço Social, em especial com a sua escolha como tema central da Revista Serviço Social \& Sociedade $\mathrm{n}^{\circ} 67$ (Cortez Editora), pelo comitê que a organizou, tendo sido incorporado, a seguir, como uma das sessões temáticas do X CBAS - Congresso Brasileiro de Assistentes Sociais/2001" (FÁVERO, 2003, p. 10).
} 
trabalho criativo, e conectado com as necessidades postas pelos usuários e a realidade familiar e social que os circundam, torna-se possível avançar em conquistas por meio das micro-ações que fazem a construção de espaços mais amplos na direção da efetivação de direitos. Experiências realizadas por assistentes sociais que trabalham em programas de assistência jurídica - em conjunto com profissionais de outras áreas, como a descrita a seguir, demonstram a efetividade dessa construção.

\section{A MEDIAÇÃO FAMILIAR COMO POSSIBILIDADE DE ACESSO À}

\section{JUSTIÇA}

As leis não bastam. Os lírios não nascem da lei.

(Carlos Drummond de Andrade)

O verso de Carlos Drummond de Andrade que aparece nessa epígrafe possibilita traduzir muitos significados. No caso da experiência do Núcleo de Prática Jurídica da Universidade Cruzeiro do Sul - AJUCSUL ${ }^{12}$, a poesia de Drummond retrata a expectativa de seus operadores, dentre eles, o profissional de Serviço Social, de não fixarem a atenção e a ação única e exclusivamente na norma posta.

O que significa entender que existem alternativas ao processo jurídico formal e que somente a letra da lei, em sua positividade, não é suficiente para dar conta da vontade e das necessidades das famílias que procuram esse serviço. Por vezes, as ações que envolvem o processo judicial não conseguem lidar com a essência do conflito familiar. Algumas das famílias atendidas pelo Núcleo apresentam esse relato, e dizem

\footnotetext{
${ }^{12}$ Experiência desenvolvida na Ajucsul do Campus Anália Franco - Núcleo de Assistência Judiciária da Universidade Cruzeiro do Sul - São Paulo. Esse Núcleo é um anexo ao curso de Direito oferecido pela Universidade, e visa a atender a população pobre da região. É operado por profissionais e estagiários da área do Direito e conta com assistentes sociais e estagiários de Serviço Social. O trabalho que realiza vincula-se ao Direito de Família, em ações de adoção, pensão alimentícia, alvará, cancelamento de separação, curatela, divórcio, guarda, investigação de paternidade, separação, entre outras.

Revista Serviço Social \& Saúde. UNICAMP Campinas, v. IX, n. 9, Jul. 2010
} 
que muitas decisões judiciais não acompanham a linha de vida familiar, ou seja, uma decisão judicial de hoje pode não contemplar a realidade da família daqui um ano. Por exemplo, se as pessoas envolvidas em ações relativas à Justiça da Família não ficarem satisfeitas com a resolução judicial, possivelmente irão recorrer novamente ao Poder Judiciário para um novo processo, uma nova revisão de alimentos, uma nova revisão da guarda de filho, a redução ou a elevação da pensão alimentícia etc., alimentando um ciclo que colabora com o aumento de processos judiciais, com a lentidão da justiça e o prolongamento de conflitos entre os membros da família. Com base nesse pensamento e analisando a realidade social e judicial nos dias de hoje, a equipe do Núcleo de Prática Jurídica da Universidade Cruzeiro do Sul considerou que seria válida a implantação de um projeto de mediação familiar. Assim, essa prática de soluções extrajudiciais teve início em abril de 2005, com a expectativa, por parte da equipe, de contribuir com a solução de conflitos que se revelavam, na sua imediaticidade, nos âmbitos interpessoal e intrafamiliar e, em conseqüência, colaborar com a redução de ações jurídicas nos fóruns locais de Vila Prudente e Tatuapé ${ }^{13}$. Com esse projeto, num período de um ano realizouse o processo de mediação com sessenta casos, o que representa cinco por mês.

A intervenção em mediação familiar tem o objetivo de possibilitar uma alternativa à família que busca solução judicial para um conflito que vivencia em suas relações internas, portanto, no âmbito da vida privada. Muitas famílias procuram o assistente social que trabalha no Núcleo e contam que gostariam de resolver ou refletir melhor sobre alguma situação de conflito familiar, contudo não querem envolver o Poder Judiciário. Assim, com base nessa demanda, buscou-se uma aproximação às técnicas de mediação familiar, não pelas técnicas em si, mas sim enquanto recurso

\footnotetext{
${ }^{13}$ Trabalham e participam do projeto de mediação familiar nesse Núcleo um advogado, uma assistente social (que atua também como coordenadora), e estagiários de ambas as áreas profissionais, na condição de observadores.
} 
operativo facilitador de um processo de reflexão sobre a vida familiar e social dos e com os sujeitos que buscavam o serviço.

Durante as atividades de mediação ${ }^{14}$ o Serviço Social tem possibilitado que sejam pontuadas questões pouco exploradas por profissionais de outras áreas, como, por exemplo, as consequências do desemprego nas relações familiares, e a insuficiência de políticas sociais para atendimento das necessidades e dos direitos dessa população. Também se busca a reflexão, junto com os profissionais e estudantes de Direito e de Serviço Social, sobre como o sofrimento dessa população interfere no âmbito processual e sobre como apoiar esses sujeitos, que procuram o advogado e outros profissionais para 'resolver' questões que se expressam no âmbito do privado, mas que cada vez mais são determinadas pelas condições sociais de vida, forjadas pela imensa desigualdade social presente na realidade brasileira ${ }^{15}$.

Trabalhar na perspectiva da mediação familiar com foco no entendimento das relações sociais é desafiante, requerendo do profissional que se encontra na linha de frente da intervenção habilidades que vão além das técnicas de negociação. Não é raro ouvir: "um bom mediador necessariamente é um bom negociador", o que pode ser bastante questionável, pois mediar uma ação que envolve a guarda de filhos, por exemplo, requer capacidade de percepção e conhecimentos que vão muito além da arte de negociar.

\footnotetext{
${ }^{14}$ Pode-se dizer que nesse trabalho existe a possibilidade de avanços em relação ao que, em princípio, poderia ser caracterizado como intermediação, ou como facilitação do diálogo. No âmbito do Serviço Social é importante a clareza a respeito das diferenças entre os conceitos de mediação familiar e da categoria teórica mediação. Mas acredita-se que seja possível aplicar os procedimentos técnicos de mediação familiar em sintonia com o projeto ético-político do Serviço Social na contemporaneidade, que tem a categoria teórica "mediação" enquanto categoria instrumental possibilitadora de transformações, na medida em que sua operacionalização esteja apoiada no "conhecimento crítico do real". Ver a respeito MARTINELLI, 1993.

${ }^{15}$ Como nos fala Koga, o sofrimento interfere diretamente nas capacidades humanas e torna-se uma medida de desigualdade social quando é possível observar que algumas coletividades sofrem mais que outras (2002, p. 43).
} 
Evidente, então, que à negociação se somarão outros conhecimentos. É fundamental que o profissional de Serviço Social que faz uso desse instrumental exercite a reflexão sobre o conjunto dos elementos que forjam a problemática apresentada, estabelecendo conexões com as determinações postas em sua construção pela questão social, e com as implicações do conflito existente, na família e no território - apenas para citar duas das categorias de análise que podem subsidiar a negociação. Sem o entendimento e a análise crítica dessas questões, a mediação será uma técnica de intervenção que poderá proporcionar a contenção, o alívio temporário de conflitos familiares, mas não contribuirá para que família e o profissional entendam as raízes e os condicionantes sociais do conflito e se empoderem para enfrentá-los.

Nesse sentido, considera-se necessário introduzir a reflexão sobre o "território" "16 onde vivem essas famílias, buscando compreender que lugar é esse, qual é sua história, como vivem as pessoas que têm participado do programa, tendo-se também a dimensão de que a escuta humanizada que o atendimento propicia é fundamental.

\subsection{DE QUE LUGAR E DE QUAL POPULAÇÃO SE FALA?}

Cada homem vale pelo lugar onde está: o seu valor como produtor, consumidor, cidadão depende de sua localização no território. Seu valor vai mudando, incessantemente, para melhor ou para pior, em função das diferenças de acessibilidade (tempo, freqüência, preço), independentes de sua própria condição. Pessoas, com as mesmas virtualidades, a mesma formação, até mesmo o mesmo salário, têm valor diferente segundo o lugar em que vivem: as

\footnotetext{
${ }^{16}$ Milton Santos define esse conceito da seguinte maneira: "O território em si, para mim, não é um conceito. Ele só se torna um conceito utilizável para a análise social quando o consideramos a partir do seu uso" (2000, p. 22)
} 
oportunidades não são as mesmas (SANTOS, 2000, p. 81).

Conhecer que lugar é esse, o território em que vivem as famílias atendidas, permitirá ampliar o entendimento a respeito de como é desenvolvido o trabalho de mediação nesse local, e pensar em possibilidades de avanços qualitativos na sua operacionalização. Dessa maneira, a discussão das categorias território e família está diretamente conectada à intervenção do assistente social na perspectiva da mediação familiar, enquanto possibilidade de efetivação de direitos.

Sapopemba ${ }^{17}$ é o bairro de origem da maior parte das famílias que participaram ou participam do serviço de mediação do Núcleo de Prática Jurídica. Oficialmente Sapopemba ${ }^{18}$ foi fundada em 26 de junho de 1910, e elevada a condição de distrito no ano de 1985, quando foi desmembrada da Vila Prudente.

A população local estimada pelo IBGE é de 282.239 habitantes ${ }^{19}$. Os que residem em favelas somam 59.608 habitantes, ou seja, 11,38\% da população total e a taxa de mortalidade por causas externas está entre 80 a 100 por cem mil habitantes. A área total do bairro abrange $33,3 \mathrm{~km}$ e tem como distritos administrativos: São Lucas, Sapopemba e Vila Prudente. No distrito de Vila Prudente, 11.047 moradores possuem renda média de até três salários mínimos ${ }^{20}$; em Sapopemba existem 37.912 pessoas com essa faixa de renda; já no distrito de São Lucas o número de pessoas com essa renda de até três salários mínimos é de 15.100 .

\footnotetext{
${ }^{17}$ Sapopemba é uma palavra tupi-guarani que significa "raiz chata".

${ }^{18}$ Segundo o MAPA da Vulnerabilidade Social da Cidade de São Paulo 2004, o bairro de Sapopemba está localizado na Zona Leste da cidade de São Paulo e compõe mais dois distritos nos quais o Núcleo também presta atendimentos, que são Vila Prudente e São Lucas.

${ }^{19}$ Dados disponíveis em: http://www.portal.prefeitura.sp.gov.br. Acesso em 20 de janeiro 2009.

${ }^{20}$ Dados do MAPA da Vulnerabilidade Social da População da Cidade de São Paulo (2004, p. 44). Características socioeconômicas dos responsáveis pelos domicílios, segundo distritos administrativos. Zona Leste. Município de São Paulo, 2000.
} 
O bairro apresenta inúmeros problemas sociais, que passam pela infraestrutura, saúde, lazer, educação e emprego. O grande contingente de famílias vivendo em áreas consideradas precárias acentua os problemas da região. O estado de pobreza que envolve regiões periféricas da cidade de São Paulo como Sapopemba, retrata as limitadas políticas sociais destinadas às famílias que vivem em áreas de risco social.

Outra situação constatada é que o número de mulheres no território é superior ao de homens, o que pode ajudar a explicar a existência da significativa parcela de mulheres chefiando famílias e, em conseqüência, a possibilidade de aumento dos índices de vulnerabilidade social. Isto porque geralmente a mulher acumula a responsabilidade pelos cuidados dos filhos e da casa com o trabalho para mantê-los, nem sempre contando com apoio e recursos por parte da rede familiar e social.

Em levantamento realizado pelo Serviço Social do Núcleo, sobre o perfil das famílias que passaram pela mediação familiar em 2005 e $2006^{21}$, categorizou-se 43 famílias, considerando motivo da procura, faixa etária, nível educacional, perfil do trabalho e bairro de moradia. Esses dados revelaram questões de natureza econômica, jurídico-sociais e socioterritoriais dos grupos familiares que se valeram dessa alternativa para lidarem com algum tipo de conflito que se revelava no âmbito da vida privada.

Os dados revelaram que é a mulher quem mais procura ações relacionadas a separação judicial, correspondendo a 37\% dos pedidos de separação, proporcionalidade que se vincula às pressões cotidianas enfrentadas por esse segmento, como chefia do $\operatorname{lar}^{22}$, em alguns casos relacionada ao desemprego ou ao trabalho precário por parte do companheiro. No quesito idade, a média geral foi de 20 a 30 anos para as mulheres, e de

\footnotetext{
${ }^{21}$ Essa pesquisa faz parte da Dissertação de Mestrado de Elisangela P. Q. Mazuelos, defendida em junho de 2009 na Pontifícia Universidade Católica de São Paulo, intitulada, Mediação Familiar: um recurso interventivo extrajudicial. O relato de experiência na perspectiva do Serviço Social.

${ }^{22}$ Disponível em: www.ibge.gov.br/home/presidencia/noticia. Acesso em 11 de janeiro de 2009.

Revista Serviço Social \& Saúde. UNICAMP Campinas, v. IX, n. 9, Jul. 2010
} 
41 a 50 anos para os homens. Quanto ao nível de escolaridade, as mulheres apresentam maior número de anos de estudo: $22 \%$ concluíram o ensino médio, enquanto dos homens, apenas $6 \%$ concluíram esse nível do ensino. No que se refere ao trabalho, a pesquisa mostrou que $50 \%$ dos homens estavam desempregados no momento da participação no processo de mediação familiar, percentual que é de $22 \%$ para as mulheres atendidas pelo programa.

Quanto ao território, a maioria das famílias, como já citado, é da região de Sapopemba, sendo que para essas famílias acentuam-se as dificuldades cotidianas quando o bairro não oferece espaços de apoio e de proteção social para a população, como conta uma moradora:

[...] Olha, o bairro tem muito pouco a oferecer, principalmente se é lá da região das favelas, tudo é longe...Tudo é difícil..

(Senhora M, em agosto de 2006)

Portanto, é necessário que a reflexão e a ação de mediação familiar vinculemse às múltiplas questões vivenciadas cotidianamente pelos sujeitos, desde entender como vivem e como acontecem as relações nessas famílias e quais são seus desafios, perpassando pelo bairro em que passam a maior parte do tempo de suas vidas; perceber como está estruturado esse território em termos de qualidade de vida, de políticas públicas, o que o local oferece, a quais acessos em termos de direitos sociais essa família terá ao finalizar o processo de mediação: poderá, por exemplo, contar com a rede de ensino, de saúde, de lazer, com trabalho? Se realizado esse link, a intervenção irá além da escuta e da negociação com vistas a uma solução imediata e judicial para a questão emergente que levou os sujeitos à procura do serviço; possibilitará que o diálogo e a reflexão tragam o contexto social mais amplo que interfere diretamente nas relações familiares postas no âmbito privado, eliminando a culpabilização 
individualizada pelos conflitos, não raro presente em trabalhos desenvolvidos com famílias.

\subsection{QUE FAMÍLIAS SÃO ESSAS?}

Conceituar e discutir família e os processos de mediação familiar, em particular com famílias em situação de pobreza, constitui tarefa complexa, levando-se em conta em especial o que já foi posto, isto é, o território onde se vive, o trabalho, a responsabilidade pelos cuidados e pelo provimento, o acesso às demais políticas sociais etc.

Conforme o Plano Nacional de Promoção, Proteção e Defesa do Direito de Crianças e Adolescentes à Convivência Familiar e Comunitária - PNCFC, a família pode ser

[...] pensada como um grupo de pessoas que são unidas por laços de consangüinidade, de aliança e de afinidade. Esses laços são constituídos por representações, práticas e relações que implicam obrigações mútuas. Por sua vez, estas obrigações são organizadas de acordo com a faixa etária, as relações de geração e de gênero, que definem o status da pessoa dentro do sistema de relações familiares (2006, p. 24).

Sarti, ao falar sobre a família pobre, afirma que ela apresenta um sofrimento maior quando existem rupturas, especialmente diante a “[...] tantas expectativas não cumpridas. Dada a configuração das relações de gênero, o homem se sente fracassado, e a mulher vê rolar por água abaixo suas chances de ter alguma coisa através do projeto casamento" (2003, p. 29).

No atendimento realizado pelo profissional de Serviço Social, observa-se a necessidade de estabelecer formas de intervenção que levem em conta, entre outros, o 
desgaste vivido por essas famílias cujos componentes, em muitos casos, buscam apenas um espaço para serem ouvidos:

Sabe, eu sou casada há vinte anos [...]. Tivemos altos e baixos, três filhos, agora praticamente adultos, conseguimos apenas nossa casa, não quero me desfazer do único bem que conseguimos.

(Senhora C, em processo de mediação - maio de 2005)

A separação conjugal significa a quebra do contrato de casamento e, portanto, implica geralmente na partilha dos bens adquiridos na permanência da união. No entanto, verifica-se que as famílias atendidas pelo Núcleo têm muito pouco a dividir. Na verdade, quando ocorre a separação, percebe-se um enfraquecimento, tanto no aspecto emocional quanto socioeconômico, com um sofrimento ampliado pela situação, não raro, de precariedade geral das condições sociais de vida. Nesse sentido, vale considerar o pensamento de Sawaia, ao afirmar que

Quando falamos de sofrimento, estamos nos referindo a um específico, ao sofrimento ético-político ${ }^{23}$, que é a dor (físico-emocional) evitável do ponto de vista social, pois é infligida pelas leis racionais da sociedade a sujeitos que ocupam determinadas posições sociais (2003, p. 45).

Nesse trabalho de mediação familiar, é recorrente a discussão sobre a divisão dos poucos bens, levando em consideração toda a história de vida construída, independentemente dos motivos da separação. Observa-se que as questões de ordem social, ou as expressões da questão social $^{24}$ presentes no cotidiano das famílias que procuram o Serviço Social do Núcleo, revelam o sofrimento provocado pelo

\footnotetext{
${ }^{23}$ Grifo do original.

${ }^{24}$ Conforme Wanderley: "A questão social fundante, que permanece vigindo sob formas variáveis nesses 500 anos do descobrimento a nossos dias, centra-se nas extremas desigualdades e injustiças que reinam na estrutura social dos países latino-americanos, resultantes do modo de produção e reprodução social, dos modos de desenvolvimento, que se formaram em cada sociedade nacional e na região em seu complexo." (2000, p. 58).
} 
desemprego, pelo alcoolismo, pela moradia precária e pelo escasso acesso a programas de proteção social estabelecidos, ou que deveriam ser efetivados por políticas sociais.

Considerando essa realidade, é possível pensar que a mediação familiar pode contribuir para que as pessoas se fortaleçam, inclusive enquanto sujeitos políticos. Nesse sentido é importante abandonar intervenções que centralizem o foco das questões em aspectos individuais, do âmbito privado, relacionados tão somente a uma ordem emocional autonomizada das relações e determinações sociais ${ }^{25}$.

Netto traz a reflexão no sentido de entender que as 'questões sociais' emergem no cotidiano e provocam, por vezes, problemas de ordem psíquica, mas, na verdade, como elemento central está a questão social. A respeito dessas situações, ele chama a atenção para o risco do fenômeno de individualização dos problemas sociais:

O lastro legitimador que se contém na psicologização engendrada neste processo está longe de esgotar-se na possibilidade, já referida, de responsabilizar o(s) sujeito(s) singular(es), na sua particular configuração individual, pelo seu destino pessoal. É óbvio que esta possibilidade tem significância: a individualização dos problemas sociais, sua remissão à problemática singular ("psicológica") dos sujeitos por eles afetados, é, como vimos, um elemento constante, embora com gravitação variável, no enfrentamento da "questão social" na idade do monopólio; ela permite - com todas as conseqüências que daí decorrem - psicologizar os problemas sociais $^{\mathbf{2 6}}$, transferindo a sua atenuação ou proposta de resolução para a modificação e/ou redefinição de características pessoais do indivíduo (é então que emergem, com rebatimentos prático-

\footnotetext{
${ }^{25}$ Para o que, ressalte-se, é importante considerar a necessidade do trabalho interdisciplinar nessa área.

${ }^{26}$ Destaque do original. 
sociais de monta, as estratégias, retóricas e terapias de ajustamento $^{27}$ etc.) (1992, p. 37).

Considera-se que em trabalhos de mediação familiar por vezes o foco da questão social pode ficar mascarado. É como se o problema central fosse outro, como se o eixo do problema fosse de ordem psíquica. Entretanto, em muitos casos, o que se observa nesse trabalho é a emergência dos problemas psíquicos, por exemplo, após a perda do emprego e da dificuldade de inserir-se novamente no mundo do trabalho.

Nesse sentido, o Serviço Social pode oferecer elementos possibilitadores da ampliação da percepção e da análise das situações. No caso do trabalho realizado pelo Núcleo, que faz uso de mediações, o assistente social busca refletir junto com os futuros operadores do Direito o quanto aquele processo está relacionado à questão social: uma pensão alimentícia que um pai ou uma mãe não consegue cumprir, por exemplo, pode mostrar muito mais do que o não-interesse no pagamento, e/ou falta de compromisso com deveres parentais; pode indicar o desemprego, o trabalho precário, a ausência de perspectivas de alterações da condição de vida em razão das transformações do mundo do trabalho, entre outros. Enfim, busca-se ampliar a percepção das questões impressas no cotidiano das famílias atendidas. O Serviço Social pode acentuar esse saber nesse espaço, ampliando a possibilidade de reflexão crítica da realidade social, pois a complexidade dessa realidade interfere diretamente nas relações familiares, movimento que nem sempre é percebido pela família que procura o serviço para a possível intervenção judiciária e muitas vezes nem pelos profissionais que a atende.

No relato a seguir, um casal procurou o serviço para efetivação da separação judicial e encaminhamento para a mediação familiar. Nos encontros de mediação, o homem expressou a seguinte dificuldade:

\footnotetext{
${ }^{27}$ Destaque do original.

Revista Serviço Social \& Saúde. UNICAMP Campinas, v. IX, n. 9, Jul. 2010
} 
O problema é que eu não consigo me recolocar, eu tenho um exímio currículo. Das quatro penúltimas empresas que trabalhei, eu fui encarregado, fui chefe de seção, gerente de setor, e o que acontece é isso, eu não consigo mais me recolocar!

Hoje tem muita gente no mercado e pouca empresa para trabalhar, a informatização da profissão não facilitou nada, muita gente fala: a informática facilitou a vida das pessoas. Para mim não, porque as empresas continuam tendo três turnos, uma máquina de operador de gráfico comporta três operadores, mas hoje numa máquina dessa tem apenas um operando. Sem emprego tudo fica mais difícil: a família fica balançada eu achei melhor me separar porque não agüento mais a pressão, é melhor enfrentar essa situação sozinho. (Senhor A, junho de 2006).

Toda a fragilidade enfrentada por esse sujeito, com consequências diretas nas relações familiares, revela situações vivenciadas por parte da população trabalhadora desta cidade. Neste caso, sua profissão era de gráfico, quase extinta pela informática e demais tecnologias disponíveis nos dias de hoje. Situações como esta demonstram como as relações familiares são afetadas pela imposição da lógica do capital, da exclusão de muitos cidadãos do mercado de trabalho, e de como estes tentam buscar soluções nos aparatos judiciais para questões que se expressam no âmbito privado, mas que são decorrentes da lógica perversa do privilégio dado ao mercado pelo capitalismo neoliberal.

Assim, a complexidade que envolve o enfrentamento de situações limite, como o desemprego, o alcoolismo, precárias condições habitacionais, morte etc., está no centro dos atendimentos realizados pelo profissional de Serviço Social nos encontros de mediação familiar. O trabalho de mediação, na ótica impressa, busca facilitar à família a reflexão associada à orientação. Dessa maneira, os sujeitos podem conversar, falar, serem ouvidos, refletir, decidir sobre suas questões conflitivas com base em maior Revista Serviço Social \& Saúde. UNICAMP Campinas, v. IX, n. 9, Jul. 2010 
conhecimento da situação vivida. Essa, é a importância do profissional de Serviço Social que realiza trabalhos como os de mediação familiar nessa perspectiva, como bem aponta Martinelli:

É fundamental que reconheçamos a importância de nossa profissão ao abrir espaços de escuta para esses sujeitos pouco alcançados por outras profissões. Com freqüência somos nós, assistentes sociais, os interlocutores desse segmento que praticamente já não mais interessa a quase ninguém (2006, p. 11).

O diferencial dessa intervenção está na possibilidade da contextualização e explicação das questões particulares apresentadas pelos sujeitos com base em sua inserção na realidade social mais ampla.

\subsection{O PROCESSO DE MEDIAÇÃO FAMILIAR E APROXIMAÇÕES À SUA CONCEITUAÇÃO}

O investimento no processo de mediação passa pelo entendimento de que o mediador é um facilitador da comunicação, devendo ser experiente o bastante, em termos teórico-práticos, para compreender a amplitude das questões que emergem no conflito ou litígio exposto pelas famílias. Assim a conceituação dessa ferramenta faz-se necessária.

A mediação familiar na perspectiva do Serviço Social, ainda numa primeira aproximação à construção de um conceito, pode ser configurada como:

Um recurso interventivo e parte da tecnologia utilizada pelo Serviço Social em sua prática. O mediador, em princípio, é imparcial perante a situação de conflito apresentada pelo grupo familiar. Seu posicionamento direciona-se para compreender e explicar os dilemas sociais que atingem a vida das famílias. 
Ele busca analisar que os conflitos de modo geral vinculam-se ao processo sócio histórico mais amplo. Assim, articulam-se as questões privadas trazidas pelo grupo familiar ao contexto social e econômico - esfera macro social.

Com essa orientação, utiliza-se o espaço da mediação para a defesa de direitos, defesa de acesso à informação, à cidadania, à desburocratização da informação, buscando com os sujeitos possibilidades para a efetivação de direitos.

Portanto, a mediação na orientação do Serviço Social, na perspectiva aqui analisada, tem como objetivo auxiliar a família nas suas questões conflitivas, propiciando espaço de escuta, apoio e orientação no momento de crise, com foco na realidade social e nos direitos sociais, além de oferecer esse serviço às famílias vulneráveis para a reflexão acerca do processo judicial solicitado, nem sempre claro aos sujeitos (MAZUELOS, 2009, p. 39).

Sobre sua operacionalização a mediação implica necessariamente no encontro com e entre as pessoas envolvidas no conflito, conforme se apresenta no imediato, afetando o cotidiano de suas vidas. O mediador atua como facilitador para que os participantes compartilhem as informações relevantes a respeito da questão deflagradora do conflito, reflitam sobre suas causas, tenham acesso à informação e construam opções para lidar com ele.

No trabalho desenvolvido no Núcleo Jurídico são possibilitados três encontros, em média: o primeiro é para acolher a família e ouvir sua história, buscar entender os pontos conflitantes; podem também ser realizadas entrevistas individuais para, entre outros, explicar qual é o encaminhamento da mediação e seu objetivo. Ouvindo todos os membros que participam do conflito familiar - que é o que vem à tona -, busca-se abrir possibilidades de maior reflexão, e essas pessoas acabam expressando como cada uma vê e analisa as questões pertinentes à situação que Revista Serviço Social \& Saúde. UNICAMP Campinas, v. IX, n. 9, Jul. 2010 
vivenciam. É freqüente nos primeiros encontros a articulação com a rede socioassistencial que trabalha com essa família. Assim, são contatadas escolas, unidades de saúde, conselhos tutelares, para que, juntos, seja possível entender a história da família e realizar encaminhamentos para recursos sociais, se for esse o caso, pois, acredita-se que antes de efetivamente os membros participarem do processo de mediação, algumas questões postas em sua vida cotidiana possam ser dirimidas, sendo que em alguns casos representantes das organizações mencionadas também participam desse processo. No segundo encontro inicia-se a reflexão sobre os componentes do conflito ou litígio e os encaminhamentos para a resolução, caso esta ocorra. No último, pretende-se tornar clara a solução que a família encontrou. Solução no sentido de algum direcionamento dado à situação, com a participação efetiva dos próprios familiares.

No Brasil - ao contrário de outros países que já desenvolvem essa atividade há vários anos, ${ }^{28}$ o trabalho de mediação familiar é prática recente, sendo que há notícias de que vem sendo pensado e implantado pelo Judiciário de alguns Estados ${ }^{29}$, bem como por organizações governamentais ou não-governamentais que desenvolvem trabalhos sociais e/ou assistência judiciária. ${ }^{30}$ Tramitam também no Congresso Nacional projetos dispondo sobre a mediação, ${ }^{31}$ enquanto mecanismo complementar de

\footnotetext{
${ }^{28}$ Países como: Canadá, Argentina, Chile, Estados Unidos, Noruega, França, Egito e Índia.

${ }^{29}$ Alguns exemplos: o Tribunal de Justiça do Estado de São Paulo tem realizado experiências piloto em alguns fóruns regionais; o Tribunal de Justiça de Santa Catarina implantou o trabalho no Estado, com equipes capacitadas para sua efetivação. Ressalte-se, entretanto, que em ambos existe a perspectiva de que esse trabalho seja desenvolvido também com mediadores voluntários, o que foge ao compromisso com um trabalho competente e de responsabilidade do poder público.

${ }^{30}$ Sabe-se também que alguns escritórios de advocacia e profissionais autônomos da área social têm se dedicado a desenvolver trabalhos utilizando o instrumental da mediação, geralmente direcionados a famílias de classe média alta.

${ }^{31}$ O projeto de lei 94/2002 (PL 4.827/1998, de origem), definido como "Método de prevenção e solução consensual de conflitos" poderá tornar obrigatória a tentativa de mediação para solucionar um conflito antes de submetê-lo ao processo judicial. Todavia o projeto subverte o caráter interdisciplinar da mediação, ao privilegiar sua condução pelo advogado, o qual poderá solicitar co-mediadores (assistente social, psicólogo ou psiquiatra), especialmente em ações que envolvem o Direito de Família. Existem outros projetos a respeito. http://www.mj.gov.br/reforma/projetos, www.stj.gov.br e www.senado.gov.br. Acesso em 29 de junho 2009.
} 
prevenção e solução de conflitos. Ressalte-se que embora as metodologias de mediação familiar mais tradicionais se aproximam mais da 'imparcialidade' posta pelo direito positivo, entende-se aqui que o seu uso pelo Serviço Social pode se dar em consonância com a perspectiva definida pelo projeto ético político da profissão, que tem na defesa e na garantia de direitos um de seus princípios centrais.

Essa alternativa vem ao encontro de questões complexas que os profissionais que trabalham junto à Justiça de Família enfrentam no dia-a-dia. Nessa linha, o assistente social não está em contato apenas com o processo formal que uma das pessoas envolvidas requer, mas com toda uma história social de vida de uma família que vivencia e expressa um conflito, uma crise, uma ruptura.

A mediação é um processo de trabalho viável por várias razões: é dada oportunidade às pessoas de dialogarem e decidirem sobre o conflito, assumindo suas decisões, ou seja, não se imputa à figura dos profissionais de determinada área profissional ou ao magistrado as decisões que os próprios sujeitos poderão tomar. A família tem a oportunidade de ser orientada sobre o trâmite processual, caso ocorra um eventual processo jurídico, pois o profissional que realiza a mediação não está, nesse momento, representando nenhum dos envolvidos. Orienta, nesse sentido, os membros da família, contribuindo para que lidem com a angústia gerada ao ingressar com determinada ação judicial sem ter conhecimento do que poderá ocorrer. Contribui para que reflitam em torno das causas sociais relacionadas à origem do conflito, e suas consequências no âmbito individual. Nesse sentido, quanto mais competente o acolhimento realizado, maior a possibilidade de reflexão, diálogo e definições entre os envolvidos.

Vale destacar que enquanto uma prática de negociação, direcionada pela “imparcialidade”, conforme já sinalizado, a mediação familiar tem sido um recurso mais 
difundido e exercido pelos profissionais da área do Direito e também da Psicologia. Considera-se, entretanto, que o Serviço Social, ainda que se tenham notícias de profissionais da área buscando inserir esse trabalho no dia a dia da intervenção, na perspectiva da transdisciplinaridade, para a negociação de conflitos, pode fazer uso da mediação enquanto instrumento facilitador do diálogo, da escuta e da reflexão em torno da situação ou das situações provocadoras do conflito - que é o que vem à tona - na direção do conhecimento e do acesso e da garantia de direitos, fundamentais e sociais.

\section{ALGUMAS CONSIDERAÇÕES}

Considerando que o Serviço Social tem entre seus princípios fundamentais a busca da equidade e da justiça social, pretende-se com essa intervenção que a família tenha a possibilidade de se colocar como sujeito de direitos e que possa de fato, ter maiores possibilidades de acesso à Justiça. Nesse sentido, vale lembrar Yazbek, quando diz que:

É tarefa da profissão propor alternativas de ação com criatividade, senso crítico e domínio da comunicação, contribuindo para que a população tenha acesso a serviços sociais básicos, na perspectiva de efetivação da cidadania (2004, p. 29).

Buscou-se evidenciar aqui a importância da intervenção do Serviço Social em programas de mediação familiar, apoiada no projeto ético-político da profissão na contemporaneidade, pois, propor formas de atender as famílias que procuram o serviço, com uma atenção e investigação mais profundas dos problemas sociais no seu cotidiano, estendendo as reflexões aos demais profissionais que compõem a equipe de trabalho, é uma das maneiras de explicitar e explicar esses "problemas sociais" com base em componentes das diferentes expressões da questão social e perceber como interferem e 
fragilizam o relacionamento entre os membros da família e destes com outros espaços e setores da comunidade e da sociedade.

Nesse sentido, o Núcleo torna-se uma referência importante para a população atendida. Muitas das famílias são quase sempre espoliadas pela questão social, categorizadas pela dificuldade de sobrevivência e com poucas oportunidades de espaços para se expressar. Cotidianamente, pode-se observar o sofrimento dessa camada da população que, via de regra, não conta com espaço de escuta e de apoio.

Conforme afirma Sawaia,

O sofrimento é a dor mediada pelas injustiças sociais. É o sofrimento de estar submetida à fome e à opressão, e pode não ser sentido como dor por todos. É experimentando como dor, na opinião de Heller, apenas por quem vive a situação de exclusão ou por "seres humanos genéricos" e pelos santos, quando todos deveriam estar sentindo-o, para que todos se implicassem com a causa da humanidade (2006, p. 102).

A família vive essa sobrecarga, que pode ser percebida na prática profissional realizada no Núcleo. Cotidianamente, o profissional depara com pessoas em estado de sofrimento, sem perspectivas, em busca de amparo legal para questões cada vez mais sociais, pois a falta de perspectiva as conduzem ao caminho judicial, ou à judicialização de conflitos familiares e da questão social.

$\mathrm{Na}$ verdade, ela quer que eu saia de casa, a lei é dela, ela quer ficar sozinha para educar os filhos do modo dela, eu não tenho domínio sobre esses filhos que também são meus, não tenho autoridade, porque não tenho um trabalho decente, ela tem! Se ela quer ficar sozinha, ela tem que dar a minha parte na casa, aí eu saio, mas ela e os meus filhos não me procurem nunca mais.

(Senhor B, em processo de mediação - agosto de 2006) 
O trabalho de mediação familiar torna-se revelador. Nesse espaço emergem histórias de rupturas de uniões, da dramática presença do desemprego, da humilhação vivenciada por muitas famílias por não contarem com proteção pública na efetivação de direito sociais e, por vezes, não contarem também com apoio da rede familiar. Isso porque, em muitos casos, essa rede também está fragilizada.

Mesmo você trabalhando, tendo seu salário, você está sempre no fio da navalha; se perder isto esse salário acabou, você vai lá para baixo, o assalariado já não é aquilo que deveria e, quando perde isto, você perde tudo - amigos e família, você não tem mais nada. (Senhor D, em processo de mediação - setembro de 2006)

O trabalho desenvolvido no Núcleo tem demonstrado que espaços que possibilitem o diálogo e permitam maior reflexão necessitam ser ampliados, sobretudo quando se trata de decisões judiciais que envolvem relações familiares, dando a oportunidade de as famílias refletirem sobre suas questões e sobre o processo judicial e seus desdobramentos, e são nesses espaços que efetivamente a prática profissional acontece. Nesse sentido, vale lembrar, conforme Fávero, que:

[...] O Serviço Social, que desde sua origem atua junto a grupos familiares, com maior ou menor ênfase, de acordo com prioridades estabelecidas pelo projeto profissional em diferentes momentos históricos, é requisitado como uma das profissões protagonistas no desenvolvimento dos diversos tipos de trabalho que se realizam nessa área (2008, p. 208).

Enfim, essa experiência de trabalho expressa o cuidado e o respeito que os profissionais, entre eles os de Serviço Social, necessitam ter com os usuários que procuram defensores para ingressar com ações judiciais, oferecendo a eles alternativas, investindo na orientação, na possibilidade de identificação das causas sociais que podem 
estar na origem dos conflitos, na comunicação entre seus membros, na facilitação do diálogo entre eles - o que por vezes os entraves e intercorrências dos processos que tramitam nas Varas de Família acabam impossibilitando ou rompendo.

Também é possível constatar que a interdisciplinaridade nesses espaços se faz necessária, pois a experiência vem mostrando que, assim, os processos assumem outra direção. Ao ouvir profissionais de outras áreas do conhecimento, aqueles que estão à frente do processo jurídico podem encontrar novos caminhos de intervenção, considerar o processo jurídico de maneira ampla, entender a interferência direta dos problemas sociais na vida dos sujeitos, trabalhar com dados afinados à realidade daquela família, o que constitui uma maneira mais eficaz de compreender e desenvolver propostas e instrumentos de intervenção qualificados para acesso à justiça por parte da população que vive um cotidiano marcado pelas expressões da questão social, no caso, da região periférica da cidade de São Paulo. Nesse sentido, a ação do Serviço Social emerge como contribuição importante para a reflexão sobre essas questões e a busca de ações conseqüentes e comprometidas com seu enfrentamento, na direção da efetivação de direitos.

\section{ABSTRACT}

The aim of this text is to raise some elements of reflection about the practice of social work as a possibility of access to justice, with prominence in an experience in legal proceedings of familiar mediation, developed in the judicial assistance area. The social work intervention particularity in this piece of work is emphasized, revealing itself as fundamental since it enables visibility to the expressions of social matters which are commonly in the origin of the disruption of social and familiar bonds that end up in judicial suits and in the family strengthening as subjects of this suits.

KEYWORDS: Access to Justice, Familiar Mediation, Professional Practice, Social Work 


\section{REFERÊNCIAS BIBLIOGRÁFICAS}

BRASIL. Lei n. 8.662, de 7 de junho de 1993. Regulamenta a profissão de Assistente Social.

CFESS. Código de Ética do Assistente Social. Resolução CFESS n. 273, de 13 de março de 1993.

CÓlMan, S. A. A formação do Serviço Social no Poder Judiciário - reflexões sobre o Direito, o Poder Judiciário e a intervenção do serviço social no Tribunal de Justiça do Estado de São Paulo 1948-1988. São Paulo: 2004. Tese (Doutorado). Programa de Estudos Pós-Graduados em Serviço Social - PUC-SP.

DRUMOND, C. A. A Rosa do Povo. Rio de Janeiro: Record, 2006.

FAVERO, E.T. Famílias, Serviço Social e Justiça - apontamentos sobre demandas e prática profissional. In: Cidades e Questões Sociais. KOGA, D., GANEV, E e FAVERO, E.(Orgs). São Paulo: Andross, 2008.

. O estudo social - fundamentos e particularidades de sua construção na área

judiciária. In: O estudo social em perícias, laudos e pareceres técnicos. São Paulo: CFESS e Cortez, 2003.

KOGA, D. Cidades entre territórios de vida e territórios vividos. In: Revista Serviço Social \& Sociedade, n. 72. São Paulo: Cortez, 2002.

MAPA da Vulnerabilidade Social. Prefeitura Municipal de São Paulo - 2004. http://portal.prefeitura.sp.gov.br/secretarias/assistencia_social/pesquisasemapas/0001/00 02. Acesso em 10.12.2008.

MARTINELLI, M. L. Reflexões sobre o Serviço Social e o projeto ético-politico. Revista Emancipação, no 6, PR:UFPG, 2006.

. Notas sobre mediações: elementos para a sistematização da reflexão sobre o tema. Revista Serviço Social \& Sociedade. n 43. São Paulo: Cortez, 1993. 
MAZUELOS, E. P. Q. O desemprego como gerador de rupturas familiares. Monografia de curso de Especialização. Cogeae/PUC-SP. São Paulo, 2006, (Mimeografado).

. Mediação Familiar: Um Recurso Interventivo Extrajudicial. O relato de experiência na Perspectiva do Serviço Social. Dissertação (mestrado). Programa de Estudos Pós Graduados em Serviço Social, PUC-SP, 2009.

NETTO, J. P. Capitalismo monopolista e Serviço Social. São Paulo: Cortez, 1992.

PNCFC - Plano Nacional de Promoção, Proteção e Defesa do Direito de Crianças e Adolescentes à Convivência Familiar e Comunitária. 2006. Brasil.

SANTOS, M. O espaço do cidadão. São Paulo: Studio Nobel, 2000.

SEADE-DIEESE. Pesquisa de emprego e desemprego. São Paulo. Disponível em: www.seade.gov.br. Acesso em 01.06.2009.

SAWAIA, B. As artimanhas da exclusão: análise psicossocial e ética da desigualdade social. Petrópolis: Vozes, 2006.

. Família e afetividade: a configuração de uma práxis ético-política, perigos e oportunidades. In: ACOSTA, R. A. e VITALE, A. M. Família: redes, laços e políticas públicas. IEE: PUC-SP, 2003.

SOUZA SANTOS, B. Introdução à Sociologia da Administração da Justiça. In: FARIA, José E. (Org.). Direito e Justiça - A função social do Judiciário. São Paulo: Ática, 1989.

WANDERLEY, L. E. A questão social no contexto da globalização: o caso latinoamericano e o caribenho. In: WANDERLEY, M. B.; BÓGUS, L.; YAZBEK, M. C. (Orgs.). Desigualdade e a questão social. São Paulo: EDUC, 2000. 